\title{
MASCULINIDADES Y PATERNIDADES EN EL CONTEXTO MINERO DEL NORTE DE CHILE*
}

MASCULINITY AND PATERNITIES IN THE MINING CONTEXT OF NORTHERN CHILE

DOI: 10.22199/S07187475.2016.0001.00005

Recibido: 07 de marzo de 2016 | Aceptado: 31 de marzo de 2016

\author{
JIMENA SILVA 1 ; CAMILA CAMPOS 2 ; PAULINA GARCÍA 3; DIEGO PORTILLA 4 \\ (UNIVERSIDAD CATÓLICA DEL NORTE, Antofagasta, Chile)
}

\begin{abstract}
RESUMEN
Introducción: el estudio de las masculinidades ha teorizado y otorgado alta relevancia a la llamada crisis de la masculinidad, la cual da cuenta de cómo una serie de cambios sociales en las últimas décadas han generado el cuestionamiento del modelo hegemónico, afectando en la forma que es vivenciado el trabajo, la familia, la pareja, la sexualidad, entre otros. Objetivo: indagar respecto a la forma en que estos elementos son construidos en las masculinidades en el contexto de una región minera del norte de Chile. Método: se realizaron 30 entrevistas a trabajadores mineros y no mineros y a sus parejas, de las ciudades de Calama y Antofagasta. Resultados: Entre los hallazgos más relevantes, se observa un refuerzo a una paternidad de proveedor y en posición de jefatura, aun en la distancia de los turnos. En este sentido, la posición de autoridad está articulada el sistema de trabajo al que adscriben y el modelo de género dominante en la cultura. En los trabajadores no mineros, la posición androcentrada como padre y pareja al igual que en los mineros prevalece aun con un sistema laboral tradicional. Conclusión: se observa vigencia de androcentrismo en ambos grupos de hombres y también en los testimonios de mujeres. En generaciones más jóvenes se aprecian algunas modificaciones en las prácticas más tradicionales, denotando una tendencia hacia el cambio y la vivencia hacia nuevos estilos de masculinidad.
\end{abstract}

PALA BRAS CLAVE: Masculinidad, Minería, Paternidad, Sexualidad, Género.

\section{ABSTRACT}

Introduction: Much of the theory on masculinity studies highlights the so-called crisis of masculinity. This crisis refers to how social changes in the last decades have affected the perception of men regarding elements such as work, family, sexuality, life as a couple, among others, questioning, as a result, the hegemonic model. Objective: To inquire how these masculinity elements are fostered in a mining region of northern Chile. Method: Thirty interviews to mining and non-mining workers and their couples were applied in the cities of Calama and Antofagasta. Results: The reinforcement of roles such as providing parent and family leader even when the father is away from home doing mining shifts is observed among the most relevant findings. This means the position of authority is connected to the work system and the model of dominant gender in the culture. Among non-mining workers, the androcentric position of father and husband is the same even within the traditional working system. Conclusion: Androcentrism is present in both groups of men; it is also perceived in women's testimonies. Nevertheless, a change in traditional practices and customs is perceived in younger generations. This might be interpreted as the beginning of a different path to new styles of masculinity.

KEY WORDS: Masculinity, Mining, Paternity, Sexuality, Gender.

\footnotetext{
Investigación realizada para obtener el grado de Licenciado/a en Psicología, que formó parte del Fondecył Regular 1150016.

. Afiliado a la Escuela de Psicología, Universidad Católica del Norte, Antofagasta, Chile. E-mail: jsilva@ucn.cl

2. Afiliado a la Escuela de Psicología, Universidad Católica del Norte, Antofagasta, Chile. E-mail: campos_9022@hotmail.com

3. Afiliado a la Escuela de Psicología, Universidad Católica del Norte,Antofagasta, Chile.E-mail:paulinag002@hotmail.com

4. Afiliado a la Escuela de Psicología, Universidad Católica del Norte, Antofagasta, Chile. E-mail: diego.portilla@gmail.com
} 
La Región de Antofagasta proviene de una larga historia de actividades mineras. Las familias de la zona se vinculan de distintas formas al trabajo minero, la influencia de esta cultura afecta a los sistemas familiares y las dinámicas bajo las que estas se constituyen, a raíz de situaciones tales como los sistemas de turnos o faenas implicadas en el sistema de trabajo minero, lo cual ha aparejado una serie de fenómenos tales como el aumento de separaciones y divorcios y desajustes afectivos y sexuales en la pareja (Guzmán y Contreras, 2012). Estos problemas se ven agravados por los modelos relacionales dominantes en este contexto. A pesar de los grandes avances en cuanto a relaciones de género, estas transformaciones han sido lentas en permear a la familia nortina, que mantiene rasgos de la cultura colonial, caracterizado por la obligada permanencia de la mujer en el hogar, al cuidado de los hijos y la administración de la familia; mientras que el hombre permanece en la mina y fluctúa, entre largas ausencias y cortas permanencias, que sin duda trae aparejado un bienestar económico y múltiples beneficios, al que otra familias no mineras no acceden (Silva y Méndez, 2013). Las personas que se desempeñan en el rubro minero se someten a condiciones desfavorables como: jornadas de trabajo excepcionales, debido a los denominados sistemas de turnos -por ejemplo: siete días de trabajo por siete días de descanso (7x7); cuatro días de trabajo por cuatro días de descanso $(4 \times 4) ; 4 \times 3,20 \times 10,10 \times 5$, etc.; horarios extenuantes, privación de compartir con la familia por días y/o semanas, entre otros (Carrasco y Vega, 2011; Meller, 2013). En el contexto minero, la rudeza del trabajo consume el cuerpo y desgasta todos los aspectos de la salud psicológica (Klubock, 1992). Entre hombres trabajadores, descansan su afectividad afianzando sus redes primarias de apoyo más inmediatas (compañeros de faena) escenario en que se reproducen estilos de cofradía y homosociabilidad histórica en centros mineros. Estos elementos favorecen la reproducción de un sistema tradicional de género androcéntrico, basado en un sistema de jerarquías, competencia, resistencia emocional y fortaleza física.

Se evidencia un rol clave de las características de género implicadas en el contexto minero, haciendo del concepto de masculinidad un elemento esencial para la comprensión de las dinámicas generadas a partir de esta forma de trabajo, en medida de que las construcciones en torno a la masculinidad ven afectadas las diversas prácticas sociales en las que participan, como la paternidad, la familia, las relaciones de pareja y sexualidad. Una posibilidad es indagar desde la perspectiva relacional de género aquellos factores presentes en el proceso de construirse como varones y padres. Figueroa (2001) considera que la paternidad es un proceso relacional que no puede suponerse al margen de la construcción del género masculino (Salguero, 2008; Olavarría 2000; Careaga y Cruz, 2006). Fuller $(1997,2001)$ señala que también existen alternativas con respecto al cuidado del otro y la empatía, rasgos atribuidos a lo femenino, pero que también forman parte de las representaciones de la masculinidad, en la cual se integra el aspecto doméstico que se asocia con la familia (matrimonio y paternidad), constituyendo así el núcleo de los afectos, el amor, la autoridad, la protección y el respeto como parte de la responsabilidad. Para algunos varones el matrimonio es un paso necesario para llegar a ser un hombre pleno (Olavarría, 2000).

Es por ello, que consideramos que un estudio que aborde las distinciones en las experiencias de trabajadores mineros y no mineros en la región Antofagasta, contribuye a comprender la construcción del ser hombre-trabajador frente a sus múltiples exigencias y la trama afectivo-relacional en que se desenvuelve. 


\section{Masculinidad y Género}

El género puede ser entendido como una práctica social, construido en contextos sociales y culturales, articulados a partir de las diferencias anatómicas entre los sexos, sin ser prácticas reducidas exclusivamente al cuerpo. Es transmitido y se reproduce a partir elementos culturales tales como el lenguaje, las costumbres y los valores; pudiendo ser transformado a partir de particularidades del contexto histórico en que es construido. (Connell, 1995; De Barbieri, 1996; Scott, 1999; Lamas, 2003).

La constitución del género se ve muchas veces vinculada a un orden simbólico mediante el cual se prescribe una relación sexo/género, con la que surge una visión del género como un concepto polar, discreto y heterosexual, bajo el que surgen identidades sexuales vinculadas con la vida reproductiva (Fuller,1997). Así, se puede considerar la masculinidad como un concepto inherentemente relacional, en el sentido que solo existe en contraste de la femineidad (Connell, 1995).

Algunos estudios sobre masculinidad (Valdés y Olavarría, 1998; Kauffman, 1999; Fuller, 2001) abordan aspectos de su construcción subjetiva en los que se da cuenta que el deseo de poder y control es un elemento clave en la formación de cada hombre, donde tener un hijo y mantener un trabajo son dos aspectos fundamentales del proyecto de convertirse en hombre, que les permite ser validados en el entorno de sus iguales. Estos aspectos de la masculinidad, cambian según las expectativas, la cultura, las necesidades económicas y las propias experiencias de los hombres como hijos, pareja y padres, que a su vez son mediadas por otros factores como raza, clase, edad, entre otras (Connell, 1995; Silva, 2013).

En todos estos procesos se constata que el lugar del trabajo en la vida de los hombres juega un rol clave. Robert Connell (1998) afirma que los escenarios y características contextuales del trabajo, las circunstancias económicas y las estructuras de las organizaciones, influyen en la forma en la cual se construye la masculinidad a niveles muy íntimos.

Dentro de los estudios de género, la masculinidad se ha estudiado principalmente en relación a la dominación masculina mediante las relaciones de género (Careaga y Cruz, 2006), esto en medida que se ha relacionado a las masculinidades con una posición privilegiada en la que obtienen un dividendo del patriarcado en términos de honor, prestigio y del derecho a mandar (Connell, 1995). En este ámbito, diversas investigaciones sobre la construcción social de la masculinidad, realizadas tanto en Chile como en Latinoamérica, plantean la existencia de un modelo hegemónico de masculinidad, que sería un elemento estructurador de las identidades individuales y colectivas en el continente (Valdés y Olavarría, 1998; Olavarría, Benavente, Mellado 1998). Dicho modelo contiene una serie de mandatos que operan a nivel subjetivo, entregando pautas identitarias, afectivas, comportamentales y vinculares, que al no ser cumplidas derivan a los sujetos en relaciones de marginalización 0 subordinación. De esta manera, se exige dar cuenta de la masculinidad en los hombres, de manera que las masculinidades no son otorgadas, sino que más bien se "fabrican" (Badinter, 1993).

Así también Gilmore, refiere que como protector, al hombre no se le permite socialmente rehuir una lucha, debe ser competitivo y orientarse al éxito. Un hombre debe demostrar constantemente ser sexualmente potente y tratar de conquistar y seducir, poseer agresividad sexual, donde el objeto de conquista son las mujeres (Gilmore en Carabi y Armengol, 2008). Además un elemento transversal a esta forma de masculinidad es que además debe ser proveedor de la familia. Entonces, de esta manera se constituyen tres de los pilares de la masculinidad hegemónica: 
protección, provisión y potencia. Complementando esta idea, Valdez y Olavarría (1998) postulan que el modelo hegemónico se experimenta con un sentimiento de orgullo por ser hombre, con una sensación de importancia. Moralmente el modelo indica que un hombre debe ser recto, comportarse correctamente y su palabra debe valer; debe ser protector de los más débiles que están bajo su dominioniños, mujeres y ancianos- además de solidario y digno.

El debate sobre qué significa ser hombre en la sociedad contemporánea, se ha convertido en la temática central en los estudios de masculinidad, haciéndose referencia a una crisis en la masculinidad (Connell, 1995; Olavarría, 2001; Careaga \& cruz, 2011), en lo que se concierne a las transformaciones relaciones entre hombres y mujeres en el espacio laboral, el espacio doméstico, las paternidades, la afectividad y el amor entre varones y el cuidado del cuerpo masculino (Carabi y Armengol, 2008). Estas modificaciones socioculturales son producto de los nuevos roles que han ido asumiendo las mujeres en el ámbito político, económico, cultural y social, así como en el complejo y privado espacio del hogar (García, 2004). Estos movimientos en la relaciones han traído consigo violencias y conflictos, que la sociedad chilena aun no logra modificar, por lo cual se mantienen estas prácticas y costumbres en las relaciones de género en la familia y la sociedad (Silva, 2013).

Trabajo y Minería

Uno de los espacios en que se hace presente esta crisis en la masculinidad es el ámbito del trabajo, esto porque se aborda el trabajo como una de las actividades fundante de la constitución masculina, a través del cual los varones consiguen aceptación, el reconocimiento social a su capacidad de producir, de generar recursos que garanticen la existencia de su familia y que le otorguen seguridad y autonomía. El rol del varón proveedor está fuertemente asentado en la actualidad, aprendiendo de sus padres que ser proveedor de la familia es ser importante (Salinas, Reyes, Romani y Ziede, 2010). En este ámbito, las condiciones laborales, los lugares de trabajo, las circunstancias económicas y las estructuras de las organizaciones se articulan dinámicamente en la forma como se construye la identidad masculina $y$ femeninas a niveles muy íntimos.

\section{Sexualidad e intimidad.}

Para comprender la tensión generada en la zona minera, abordaremos en primer lugar las transformaciones en la vida activa y sexual, que se generan en los distintos trabajadores. Para ello, en primera instancia señalar, que la sexualidad la entendemos como la producción sociocultural relacionada al placer producido por los cuerpos sexuados en los seres humanos, siendo este el producto de un proceso cultural de aprendizaje (Donoso, 2002; Weeks, 1998; Giddens , 1998). La sexualidad se organiza dentro de los sistemas sexo/género, el cual define las relaciones entre hombres y mujeres, o bien entre hombres, estableciendo así las formas en la cual los sujetos se organizan y distribuyen en sociedad (Lagarde, 2001). La sexualidad, la ternura, la intimidad, el placer $y$ en definitiva, todo el comportamiento sexual, son productos sociales y es la sociedad, con su intrincada red de creencias, conceptos, papeles y actividades sociales, la que impone las restricciones de lo que se considera permitido y esperable en determinado período histórico (Weeks, 1998).

Ahora bien, dentro de las interacciones atravesadas por las relaciones sexo-genero, se dan dinámicas desiguales, construyéndose bajo el dominio de lo masculino sobre lo femenino, dándose paso a comportamientos y hábitos de dominación y violencia en la cotidianeidad, los cuales se expresan mediante prácticas de machismo y micromachismo. Este último, se caracteriza 
por ser practicado de manera inconsciente y de manera casi imperceptible, a través de los que se mantiene la posición de género dominante, articulando una limitación de la autonomía en la mujer a través de discursos cotidianos $y$ sutiles que tienen a naturalizarse $y$ no ser mayormente cuestionados (Instituto Vasco de la Mujer, 2008).

En directa relación con las relaciones de pareja y la sexualidad existe el constructo de intimidad, que adquiere expresiones particulares y diferenciadas entre hombres y mujeres (Muñiz, 2002). En relación a esto, la valoración de la intimidad en las masculinidades, se encuentra ligada a una cultura de género, la cual no solamente modela cuerpos y psiquismos que asumen identidades y posiciones simbólicas y sociales, sino que también implica posiciones, lugares y relaciones de poder (Muñiz, 2002; Cruz, 2011).

En complemento con esto, en el ámbito de las masculinidades se ha vinculado la sexualidad masculina con "el deseo irrefrenable y el ser activo sexualmente, característica que se simboliza y actualiza en la penetración sexual" (Donoso, 2002, p 61). En estudios realizados en Chile, se ha señalado la intimidad y la sexualidad como un elemento esencial y de gran importancia en las masculinidades, de manera que el inicio de la sexualidad activa constituye un momento de socialización para el varón, a través del cual puede afirmar su identidad masculina (Valdés \& Olavarría, 1998).

\section{Paternidad}

Al considerar la paternidad como una construcción cultural, se toma en cuenta la variabilidad histórica, ligada a determinados contextos políticos, económicos y sociales; así como ciertas configuraciones simbólicas e imaginarias (Parrini, 2000). Es decir será construida de manera específica en cada sociedad y al mismo tiempo reafirmado por ésta.
Para que se considere a un hombre como un varón adulto y representante de la masculinidad dominante, es necesario que ejerza su rol paterno de la mejor manera, ya que este se considera constitutivo de la masculinidad. Palacios y Valencia (2001) se refieren a este aspecto cuando hablan del matrimonio como la puerta de entrada a la masculinidad adulta, pero que la paternidad la constituye en su foco esencial, ya que conecta tres características fundamentales: procrear, socializar y sostener económicamente a los hijos(as). Así se le asigna la autoridad al hombre en el grupo familiar; Rivas y Rodríguez (2008) lo caracterizan por la responsabilidad de proveer los medios de subsistencia y representar a la familia en el espacio público. A su vez, en el sistema de parentesco y en el sistema sexo - genero, la paternidad se remite al orden del sentido y la significación, es decir el sentido que adquiere para un hombre el ser reconocido como padre por un niño, por ende cumple la función de integrar a un sujeto a una cultura determinada (Parrini, 2000).

No obstante, en investigaciones más recientes, se señala que los hombres más jóvenes manifiestan involucrarse activamente en la reproducción, en ser partícipes conscientes en la concepción de sus hijos, así como su crianza y acompañamiento (Olavarría, 2004), en desmedro del mandato imperante, en donde existe un orden social, que impone que el varón debe mantener su calidad de padre protector y proveedor de sus hijos y más aún como observador de la reproducción de sus mujeres (Olavarría, 2004)

\section{MÉTODO}

\section{Diseño Metodológico}

El enfoque metodológico al cual adscribe la presente investigación corresponde al paradigma interpretativo, asociado a una metodología cualitativa. Lo anterior nos permitirá comprender y conocer las implicancias del fenómeno de la 
construcción de la masculinidad en el ámbito laboral; de pareja y paternidad de los hombres antofagastinos. En este ámbito, buscamos comprender la información a partir de los relatos de los protagonistas, para ello utilizaremos la entrevista abierta semi-estructurada. Dicha entrevista estará destinada a explorar y profundizar los ejes centrales de la investigación; trabajadores minero y no mineros, significación de la masculinidad y su vínculo con la paternidad y la parejas. La información se recopilará de acuerdo a las dimensiones: dinámica familiar, estilo de paternidad, negociación de conflictos y prácticas laborales/ recreación. Al mismo tiempo de manera complementaria se utilizara una encuesta sociodemográfica.

\section{Unidad de Análisis}

Resulta relevante desarrollar el estudio en la región de Antofagasta, dado que esta constituye el núcleo productivo de explotación minera de cobre más importante de Chile (Meller, 2013). Se seleccionó a un grupo de 22 varones, de los cuales 11 de ellos son mineros pertenecientes a empresas mineras ubicadas en la región, tanto de la ciudad de Antofagasta como Calama, mientras que los 11 restantes son hombres dedicados a trabajos que no están vinculados directamente con el rubro minero. En ambos casos, el rango de edad del grupo fluctuó entre 20 hasta 65 años, dado que en estas edades se pueden encontrar varones insertos en el sistema laboral tanto en el sector minero, como no minero y así también, el límite de edad de 65 años, nos permite abarcar a la población cercana a la edad de jubilación. Entre los criterios de inclusión considerados se encuentra: ser hombre, poseer un contrato de trabajo, ser padre, independiente del estado civil en que se encuentre. Asimismo, se entrevistó a un total de 9 mujeres esposas de trabajadores tanto mineros como no mineros, a quienes se les pregunto sobre sus valoraciones y vivencias en relación a sus esposos y la forma en que estos compatibilizan espacios familiares con los de trabajo. Los criterios de inclusión para estas fue: Ser madre, mantener una relación de pareja con un hombre trabajador de la región de Antofagasta.

El contraste entre los trabajadores del área minera y no minera se realizó en base a los cargos ocupacionales de sus respectivos trabajos, a su vez, estos cargos son posibles de comparar a partir del nivel educativo que requiere cada uno.

\section{Procedimiento y limitaciones}

El proyecto fue aprobado por los comités de Ética de FONDECYT y de la Universidad Católica del Norte. Es importante señalar que durante el proceso en terreno, hemos enfrentado la expresión de evitación 0 protección de la intimidad, la vida privada amorosa o sexual por parte de algunos trabajadores. Esta puede constituirse en una limitación en torno a la comprensión de la vida en pareja del trabajador. En este mismo plano, la participación de las mujeres parejas dio cuenta de mayor soltura $y$ disposición. A través de ellas logramos complementar algunos escenarios sobre intimidad y sexualidad.

Buscando comprender, como los trabajadores mineros y no mineros de Antofagasta, significan su lugar como padres en la familia, hemos realizado una selección de microtextos organizados en los siguientes ejes: 1) Compatibilidad trabajo- paternidad, 2) Compatibilidad trabajo- sexualidad y pareja 3) Compatibilidad trabajo - familia.

\section{RESULTADOS}

Análisis interpretativo de los hallazgos.

1. Compatibilidad Trabajo - paternidad

1.1.Estilos de paternidad.

Expresión de afectos.

Hombre minero 48 años, 4 hijos, Antofagasta: 
Lo he ido aprendiendo, mi señora me lo va diciendo, "sabes que ten una forma más cariñoso con los niños" (...) yo reconozco que me falta un poco más y el hecho de trabajar afuera, cuando yo era más joven me iba (a jugar) a la pelota por ejemplo... si tus compañeros los ves todos los días.

Hombre no minero, 36 años, 2 hijos, Antofagasta

Sí, yo creo que si porque lo veo en el comportamiento que tienen, tienen un respeto hacia uno. Yo creo que eso es por la cercanía que hay en ellas a pesar que sus papas estén separados, no me he alejado y el trato con ellas sigue siendo el mismo y le demuestro harto cariño, todos los días un te amo un te quiero.

En las experiencias de trabajadores mineros y no mineros, se observan diferencias en la expresión de afectos padre-hijos/as. Estas distinciones, pueden articularse a distintos procesos; la construcción de masculinidad entre hombres mineros, con mayor distancia de los afectos, socializados bajo una apariencia de rudeza y resistencia que enmascara las expresiones de amor familiar. Esta distancia es atravesada por el modelo productivo de las empresas y por los cambios socioculturales que van modificando el ser hombre-padre. En el trabajador minero, la resistencia emocional se ve reforzada por las presencias y ausencias de la vida de los hijos en el contexto laboral por turnos. En este relato, el trabajador es capaz de reflexionar acerca de sus dificultades relacionales y de afecto con sus hijos, y se observa capacidad de recepción al consejo de la pareja. El trabajador no minero, por otra parte manifiesta su necesidad de retroalimentar los afectos de las hijas, aún en una situación de ruptura conyugal. Esta situación, no le impide empoderarse en su lugar de padre. A diferencia del trabajador minero, tiene su favor la opción de estar presente a diario en la vida de sus hijas en las distintas etapas de la vida. Su lugar como padre se refuerza en su posición discursiva, donde hace hincapié en la representación que hace del reconocimiento que él siente de sus hijas, como padre afectivo.

En estos dos trabajadores se observan algunos rasgos distintivos entre una masculinidad hegemónica y las nuevas construcciones de masculinidad. Estas distinciones pueden relacionarse con los cambios socioculturales y de género, que han modificado los estilos de paternidad. Estos cambios permean con más o menos implicancias, dependiendo si es un padre joven o padre mayor. Entre los más jóvenes observa que optan por participar activamente en la relación con sus hijos, tanto como proveedores, como en el constante acompañamiento de los procesos psicosociales de los hijos (Olavarría, 2004).

\section{Educación y crianza.}

En los siguientes discursos de los trabajadores, se aprecia la necesidad de reconocimiento por su esfuerzo en la realización de su lugar como proveedor, en ambos discursos se aprecia un desajuste emocional de padre e hijo. Es así como la figura paterna alimenta su estatus de poder y prestigio al interior del hogar (Olavarría, Benavente y Mellado, 1998).

Hombre no minero, 59 años, con dos hijos, Antofagasta.

Uno hinchó que quería unas zapatillas, le compré las zapatillas, y salió con que "no me gusto el color". Entonces con harto esfuerzo yo se la compre, y para que después me la rechazara, (...) con tanto amor ahí, se llevó un par de palmazos. 
Hombre minero, 48 años, cuatro hijos, Antofagasta

El castigo en el fondo me dolió a mí. Yo le había comprado ese autito, como una hora antes y no lo quería, entonces le digo, ya que no lo quieres -toma- y se lo regalé al niñito que estaba al lado.

Para todo hombre inmerso en el mandato hegemónico de la masculinidad, resulta de gran importancia el reconcomiendo de los hijos y la pareja de su lugar como padre y la injerencia que puede tener en la relación con los hijos: admiración, obediencia, ser un modelo que seguir. Este trabajador espera obediencia y aceptación del hijo e impone su efecto en la representación del regalo. La frustración emerge cuando lo que espera del hijo no se hace real, en su reacción busca castigarle, haciéndole sentir su capacidad para retirar el afecto.

\section{Convivencia.}

En los siguientes relatos, se representan escenas en la rutina familiar en un estilo comunicacional establecido a lo largo de la vida con los hijos. La escena manifiesta ciertas distancias en el grupo, sin que por ello falte una cuota de afecto que se observa en la preocupación por las actividades de cada uno.

Mujer pareja de minero, 50 años, 2 hijos, Calama

Cuándo estamos en la casa salimos a hacer las compras juntos 0 cualquier trámite 0 simplemente miramos televisión y conversamos sobre los niños o cómo ha estado el día de cada uno. En las tardes casi siempre esta cada uno en su pieza o haciendo cosas suyas; cuando más hablamos y compartimos es en la noche cuando nos juntamos a tomar té, casi siempre nos quedamos mucho rato después por que nos ponemos a conversar.

Hombre minero, 35 años, un hijo, Calama

Voy a llegar a la noche, y mi hijo está durmiendo. En la mañana se levanta y se va al colegio, tampoco lo veo. Tengo cuatro días que para mí son para compartir con él, pero no comparto mucho porque él tiene su propio mundo ahora: el play station, los amigos, entonces me deja un poco de lado.

Este relato, el padre da cuenta de cómo la organización del trabajo lo ha alejado de la socialización con el hijo, realizando actividades independientes. El estilo de paternidad que este trabajador ejerce sugiere conformismo en tanto asume estar "en otro lado" de la vida del hijo.

Se da cuenta de una relación, en la cual el acompañamiento y apoyo entre familiares no implica necesariamente de la presencia física constante entre los miembros, sin embargo se busca generar espacios de comunicación entre los miembros de la familia. Además, denota un estilo relacional más clásico, diferente a las dinámicas de crianza que son más propias de padres más jóvenes.

En el siguiente relato se aprecia, como el trabajador no minero se encuentra situado en un lugar de hombre-padre activo en la crianza y la educación de los hijos. Este trabajador se encuentra entre la exigencia de la empresa, el deseo de estar presente en la vida de los hijos y el atractivo económico que significa frente a la necesidad de asumir el mandato a proveer.

Hombre no minero, 38 años, tres hijos, Antofagasta

Lo voy a dejar a entrenamiento y ver los partidos igual a veces. Cuando tengo tiempo lo voy a ver, $y$ 
en la semana entrenan de noches entonces, yo que llego a la casa y los espero con sus dos amigos que son del colegio, los paso a buscar en auto y los llevo a entrenar y después de que entrenan los vuelvo a traer.

Se observa, los trabajadores no mineros poseen más opciones para involucrarse como padres-presentes y activos en la crianza y acompañamiento de los hijos (Olavarría, 2004). Esta opción no sólo se relaciona con el trabajo, sino también con el sistema sexo/género de base en la socialización de la masculinidad. En este sentido, el relato da cuenta de una adscripción a la nueva masculinidad, que avanza en la deconstrucción de la ubicación de hombres y mujeres en la escena familiar. Esto significa, que la participación en el trabajo doméstico, de crianza y cuidados no le resta valor a la hombría y abre caminos hacia una familia con mayor democracia de género y capacidad de negociación (Connell, 1995).

Hombre minero, 38 años, un hijo, Antofagasta.

Muchas navidades, año nuevo, fiestas patrias, en los cumpleaños del hijo de mi señora, de los míos propios. Fiestas importantes y fechas importantes que me han tocado trabajar, pero tenemos que hacernos a la idea nomas.

El trabajo en minería supone una alta exigencia física y psicológica por el estilo laboral asociado: largos turnos, aislamiento de los centros urbanos, distanciamiento de la familia, pérdida de eventos significativos. Este estilo laboral ha generado en la familia del área minera distintos conflictos; en este ámbito, existen rasgos de alienación laboral y económica (Salinas, Romani, Ziede, 2010) del hombre-padre-trabajador minero, frente a la exigencia de la empresa a cambio de un salario más elevado que en otros trabajadores de igual profesión (Silva, 2012; Carrasco y Vega, 2011).

El hombre minero al priorizar el trabajo y sacrificar partes de su lugar en la familia, debe enfrentar el costo en sufrimiento, sentimiento de no reconocimiento y el embate del sentimiento de conformismo. Este último, porque no se encuentra obligado, es una opción que conlleva grandes beneficios económicos, que no ofrecen otras empresas a cambio de su entrega, y que le permiten percibir mayor poder económico, lo cual lo mantiene en la jefatura y le facilita mantener un nivel simbólico elevado, que alimenta su masculinidad al poseer un prestigio superior a otros trabajadores chilenos.

\section{Compatibilidad Trabajo- Sexualidad y pareja.}

2.1. Relaciones de pareja.

Tiempo compartido.

En este modelo laboral, la relación de pareja del trabajador minero forma parte del conglomerado que maneja la empresa. Es decir, así como está organizado el trabajo desde la empresa, este modifica todos los aspectos de base del hombre y la mujer: el tiempo de ocio, las horas de sueño, el ejercicio de paternidad/maternidad, afectividad y sexualidad entre otras.

Hombre minero, 38 años, casado con un hijo Antofagasta.

Igual salimos, de ir a comprar, a ver algo al Mall, al centro. La acompaño al supermercado a la feria, ¿porque no?, a lo que sea necesario que yo le pueda ayudar.

Mujer pareja de minero, 29 años, casada, 2 hijas, Antofagasta.

De vez en cuando tratamos de salir, de hecho queremos salir este fin de semana, pero... Lo que pasa es que 
como él llega el día jueves hasta el día domingo. Igual esos días se pasan muy rápido. Hay veces que tenemos que hacer muchos trámites (...) y el día domingo ya después a la noche con suerte podemos ver tele. Entonces lo que pasa es que yo estoy muy cansada y de verdad prefiero quedarme en la casa a descansar.

Entendiendo la intimidad como una trama afectiva donde se teje el amor, el erotismo, la vida cotidiana de la pareja con la familia, este trabajador es visto por su pareja, como un acompañante, que se incluye en actividades económicas- administrativas de la familia. La intimidad de la pareja es representada como un sin fin de trámites y responsabilidades que encaran juntos. No se logra visibilizar el encuentro amoroso, pues el relato sugiere un estado de cansancio donde ambos desean reposo.

\section{Valoración de la pareja.}

En algunos relatos, los trabajadores valoran a sus parejas positivamente, a partir de su ubicación en el sistema sexo/genero. Una posición que valida la distinción público privado y la alimenta, convenientemente. En ella además las mujeres que se sitúan subordinadas se acomodan y saben manejar las situaciones. Esta ubicación se encuentra principalmente en parejas mayores.

Hombre minero, 62 años, casado, 5 hijos, Calama.

Mi señora es una casta en extinción. Yo le digo que es muy tolerante, muy pacifica, muy lejana a la discusión. [Se le pregunta por la resolución de conflictos] Yo he sido un tipo muy "cabrón", en las decisiones. Todo lo que se ha hecho, todo lo que tenemos, jhan sido decisiones mías!, no a escondidas ni mucho menos, se daban las oportunidades y yo las tomaba, para bien o para mal.
Mujer pareja de minero, 50 años, casada, 2 hijos, Calama

Creo que mucha (importancia), porque sabe que soy la única persona que se encarga del hogar y así él se puede dedicar sólo a su trabajo, sin mayores preocupaciones.

Ambos discursos logran dar cuenta de la presencia y vigencia del tradicional sistema de jerarquías de género donde el hombre se representa como jefe, y la mujer ejerce poder en espacios domésticos (Lamas, 2000; Fuller, 2000; Montecino, 2002). En este ámbito doméstico, el sujeto valora a su pareja como una figura idónea que reconoce el lugar de cada cual en la escena familiar, lo cual le permite sostener su posición de poder y hombría. En el relato de la mujer de 50 años, se identifica la fuente del valor y prestigio social, en el desempeño eficiente de la admiración del hogar. El trabajador en este modelo necesita la figura de la madre-esposa que le otorga reposo y cuida su prole y su espacio, así se logra dar continuidad a la familia tradicional (Lagarde, 2001).

\section{Afectos hacia la pareja.}

En el estilo afectivo relatado por los trabajadores, se pueden encontrar violencia, rasgos de rudeza, que puede ilustrar partes de la dinámica que opera en la intimidad.

Hombre minero, 35 años, tres hijos, casado, Calama.

No, es que sabes, no lo pide porque sabe que no lo voy a hacer. Ella me lo ha dicho, "como te voy a pedir un ramo de flores si tú si siempre me has dicho que las flores son para los muertos" pero, yo a veces me he mandado "cagadas", yo sé que le gustan las cosas de oro entonces le llevo un engañito como que pase piola. 
Mujer esposa de minero, 55 años, casada, 2 hijos, Antofagasta

No le cambiaría nada. Porque no me lo imagino por ejemplo romántico 0 así empalagoso, al principio era muy romántica, soñadora, pero como que el hombre también a uno la amolda (...) a estas alturas ya más maduros no, estamos bien como somos.

En la intimidad se devela las distinciones que han socializado a hombres y mujeres de este grupo; hombres alejados de los afectos, y mujeres que en la ausencia del cariño se acomodan a una vida menos expresiva con la pareja. En la intimidad de la sexualidad, la ternura, el cariño y la expresión de las emociones estarán construidas con partes importantes de las costumbres, creencias, papeles y actividades sociales compartidos en las prácticas del contexto. En estos relatos se aprecia, como se significa el romanticismo en parejas con distintos niveles de convivencia (55 años/35 años) tanto en la representación femenina como masculina.

\subsection{Sexualidad}

\section{Situación de intimidad.}

El amor romántico puede estar en remisión entre los trabajadores, se observa resistencia a la expresión las emociones por parte de los hombres. Una posición que los autores han identificado como cierto grado de temor a situarse en el ámbito de lo femenino (Connell, 1998). El romance, la ternura, los gestos de dulzura se le atribuyen a las mujeres, como parte de su ámbito afectivo, entre hombres éstas pondrían en duda su hombría, por lo que se reprimen (Olavarría, 2004).

Hombre minero, 35 años, tres hijos, Calama

¡Soy lo menos romántico! [Refiriéndose a su pareja] Lógico que pide gestos, pero lo que pasa, es que ya nos conocemos por tanto tiempo, que ella ya sabe cómo soy yo, y yo sé cómo es ella, [Se le pregunta cómo es su pareja] ¡Es súper pegote! es súper tierna. Entonces, yo creo que es un complemento (...) yo soy el ogro y ella es la dulce.

Citando la metáfora del trabajador sobre la personificación del ogro y la dulce, podemos decir que ésta se desprende de un modelo de relaciones de género dicotomizadas $y$ motor de las relaciones de poder en la pareja. Este modelo sitúa al hombre con una emocionalidad restringida, asociada a mantener su sitial de poder y distancia afectiva;) plantea que en este modelo, "los hombres esconden sus sentimientos para guardar la información que podría darles a otros algún poder sobre ellos" (Middlenton en Cruz, 2011); en contraposición se representa a las mujeres, socializadas para expresar y demandar afectos, de emociones lábiles, débiles, sutiles y románticas.

Hombre no minero, 59 años, Casado con dos hijos, Antofagasta.

Entonces quedó como un tabú para ella (infidelidad) tuvimos un problema, volví a recaer al año después, había un hijo de por medio. La relación (paralela) se siguió manteniendo, porque yo tenía que aportar (mantención del hijo fuera del matrimonio) (...) y estuvimos a punto de separarnos (...) y de ahí para delante es tabú. No conversamos sobre el tema porque nos afecta mucho (...) (ella) dejó pasar el asunto, profundizar en el tema es complicarle la vida a mi pareja (del matrimonio).

Resulta útil, comprender el lugar de las mujeres en este relato: una de ellas es situada fuera de lo legitimado por el modelo social de prestigio vigente. $Y$ la otra es 
situada susceptible, debilitada por la presencia de una familia paralela: un hijo y una mujer con quienes el trabajador asume responsabilidades. Este modo de establecer triángulos sexuales, afectivos y económicos se pueden considerar un disparador de conflictos y violencias en la pareja. Estos conflictos quedan en un plano oculto, lo que va minando la confianza y seguridad de la pareja, ella calla, pero sabe y este saber se entrama en la intimidad.

Este estilo de relaciones se mantiene históricamente en Latinoamérica, sostenidas por discursos y prácticas androcentradas, que son alimentadas a su vez por la creencia de unas necesidades sexuales imperativas en el hombre (Olavarría, 2004; Connell, 2000; Weeks, 1998). En estos, se asocia la infidelidad y la poligamia como una práctica masculina y femenina arraigada en la cultura.

Mujer pareja de minero, 52 años, casada con dos hijos, Antofagasta.

Del $7 x 7$ yo le puedo hablar. Bueno, llega y es un hecho que se pone al día, antes de irse también (intimidad sexual), Pero ¿sabe que me he dado cuenta yo? que cuando él llega es como un extraño, -te fuiste tantos días- y nunca fue así antes, y el segundo, tercer día ya empezamos a conversar y le toca (afectos, sexo) los 7 días antes que tiene que irse.

Estos aspectos laborales que se entraman en la cercanía e intimidad de la pareja, entre largas ausencias y regresos forman parte en las estrategias amorosas y eróticas de la pareja. Se puede decir, que en la calidad del vínculo de la pareja y sus vaivenes, interviene el programa de la empresa (Barrientos, Salinas, Rojas y Meza, 2008).
Valoración de la sexualidad.

En los siguientes relatos se observa como los trabajadores valoran la sexualidad:

Hombre minero, 62 años, 5 hijos, Calama.

[Se le pregunta al entrevistado acerca de su situación de intimidad con su pareja] _"No" si esta toda jodida de las rodillas, ¿Qué voy a hacer?! “toy cagao"!

[El entrevistado se refiere a la necesidad de tener un amante por la condición de salud de su pareja]iSi igual hay que elegir una amante por ahí!, pero "bien", "piola". $Y$ esto para ser así como justo, es súper, ¿cómo te dijera yo? ¡Novedoso! Los pocos momentos que tienes y uno que tiene que hacer ;"disfrutarlo"! entonces no hay peleas, hay pura sintonía.

Hombre no minero, 59 años, casado con dos hijos, Antofagasta.

Como te digo yo, el problema está en el motivo de infidelidad que yo cometí. Fue, una dejación de ella respecto a lo amoroso o la parte afectiva. No había mucha relación en ese sentido, ella normalmente rechazaba. Cuando yo quería tener algo (...) rechazaba, había un motivo de rechazo, siempre había una excusa de algo, entonces (...) Yo salía hasta que paso algo (...) comencé a tener una relación con alguien por fuera, hasta que me pillaron.

Esta experiencia de búsqueda de ser reconocido como sujeto afectivo, puede estar vinculada a desajustes, creencias y prácticas de la vida íntima de ambos trabajadores y sus esposas. En la homosociabilidad cotidiana, en compañía de otros hombres, se encontrará con similares discursos sobre los valores dominantes de 
hombría. Estos se enfocan principalmente en idearios donde la mujer otorga placer al hombre y su lugar en la escena de la intimidad sexual es satisfacer, por sobre sus deseos. A lo anterior podemos aludir a lo analizado por Gilmore (2008), en relación a las exigencias sociales que recaen sobre el hombre, el que debe mantener potencia sexual, conquista, seducción y agresividad sexual. En este estilo de sexualidad, se encuentran mujeres que demandan respuestas sexuales y eróticas en afirmación del hombre potente, con alto rendimiento.

Mujer pareja de minero, 38 años, casada con dos hijas, Antofagasta.

\begin{abstract}
D en la cama está bien, pero no es despampanante. Le falta pasión, fuerza, esta cosa masculina caliente. $D$ es más suavecito, más gentleman, y a mí como mujer me gustaría que se chasconeara más. $D$ es muy tradicional y cuando he tratado de innovar, igual quizás he sido muy directa o poco atinada, la cosa es que se ha sentido mal. Entonces, mejor, la innovación hacerla por fuera. Pareja abierta y ya está.
\end{abstract}

En estas representaciones de la intimidad sexual, ella desea intensidad por sobre el romance y la suavidad, que tradicionalmente se atribuye al deseo femenino. Se observa un desajuste en la negociación sexual; el hombre recibe la demanda como interpelación que puede poner en cuestión su capacidad, virilidad y agresividad sexual, lo que dejaría en entredicho su hombría.

\section{Compatibilidad Trabajo- Familia.}

\subsection{Dinámica familiar.}

\section{Participación en actividades domésticas.}

Hombre minero, 38 años, casado, dos hijos, Calama.
Estábamos con una sola niña que ya es grande, ahora, que llegará una guagua a la casa (...) trato de que ella no se lleve todo el peso. Entonces trato de ayudar en lo que más pueda: lavando la loza, haciendo (...) aseo, limpiando el patio o haciendo almuerzo, me complemento en todo (...).

El estilo de este trabajador se sitúa entre los que avanzan hacia las nuevas masculinidades. Se aprecia deseo de equidad al momento de compartir labores en el hogar, estas prácticas tradicionalmente han sido pensadas terrenos exclusivos de las mujeres. Con los avances socioculturales y de género, en las parejas jóvenes se observa una compresión de la participación activa en la crianza y cuidado del hogar y los hijos, lo que da cuenta de una apertura en torno a nuevas identidades masculinas, así como femeninas. Aun así, este trabajador da cuenta de que estas tareas no son necesariamente responsabilidades propias, adoptando una posición de ayuda, dando cuenta de que quien principalmente se encarga de estas tareas es su esposa.

Mujer esposa de minero, 50 años, casada con dos hijos, Calama.

Soy la encargada de que todo funcione. Soy la única persona que se preocupa de mantener el hogar, así que el funcionamiento de la casa depende en su totalidad de mí (...) me pide (su esposo) que descanse y no haga tantas cosas en un solo día. También se preocupa de que me esfuerzo demasiado, sobretodo porque tengo problemas a la rodilla y no debería exigirme. A veces me dice que deje las cosas así, que descanse primero y después sigo. Pero muy rara vez se ofrece a ayudar. 
El sistema dicotomizado sexo-genero divide el orden social entre espacios y funciones masculinas y femeninas; marcando así el valor y prestigio de cada una de las tareas según quién las realiza (Lamas, 2000). Es posible apreciar en el relato el valor y prestigio del trabajo doméstico en el hogar. Al mismo tiempo, se aprecia como su pareja conserva su lugar como proveedor descomprometido con la dinámica doméstica, si bien expresa preocupación por el cansancio de su mujer, no evidencia motivación alguna por efectuar alguna labor doméstica.

\section{Actividades recreacionales.}

Hombre minero, 38 años, casado con un hijo, Antofagasta.

Nos gusta viajar, y no solamente viajamos para las vacaciones, pero también lo programamos con los descansos hasta los cuatro, cuando estaba cuatro por cuatro, también salíamos de vacaciones, tratábamos obviamente de pasarlo en familia, disfrutar y pasarla bien. Ahora cuando estamos con el siete por siete con mayor razón en cualquier día del año, cualquier semana del año que me toque con descanso, podemos programarnos para un viaje, y así hemos viajado varias veces. $Y$ sobre todo en las vacaciones que ya son alrededor ahora de 35 días con mayor razón.

Hombre no minero, 41 años, separado, dos hijos, Antofagasta.

Llega la vacaciones de verano y aprovechamos de ir a la playita, una vuelta a la portada, invitaciones a San Pedro que tenemos ahí congeladas, tenemos pura ganas de ir, pero quizá ahora podamos ir a dar una vuelta conocer pero si tengo hartas actividades como mis hijos.
En ambos trabajadores, adultos jóvenes, valoran el tiempo compartido en familia, y develan como el sistema laboral penetra en sus vidas y la de su grupo. Lo que puedan planificar fuera del trabajo dependerá del tiempo que les reste de los programas de la organización productiva de cada empresa. Esta sujeción laboral, es parte de las opciones que han realizado y las familias deben compartir con ellos esta dinámica.

\section{Distribución de recursos.}

Hombre minero, 38 años, Casado con dos hijos, Calama.

Yo administro, trato de no darle preocupaciones a mi pareja, aunque gano buenas "lucas" trato de que, (...) no se preocupe por lo que hay que pagar, eliminarle la carga. Ella también tiene sus tarjetas, tiene derecho a tener el dinero. Voy más por el asunto de las cuentas que uno puede tener, los créditos hipotecarios que siempre existen, entonces por ese lado yo trato de manejarme.

Hombre no minero, 59 años, casado, 2 hijos, Antofagasta.

O sea si igual hay confianza (...) pero más que nada soy yo el que manejo más la plata de las cuentas las llevo yo, la plata la manejo yo. Ahora ella tiene su propia plata entre los niños, ella sus hijos ahora que están todos trabajando, todos le pasan plata y ella maneja más plata ahora, bueno después de varios años que está manejando más plata.

Mujer pareja de minero, 32 años, casada, un hijo, Antofagasta.

En un principio cuando nos empezamos a distribuir las tareas del hogar quedamos en que las cuentas nos íbamos a dividir mitad y mitad. Sucedió que las tareas que a 
él le tocaban, se le olvidaban y se acumulaban, entonces dije, a mí no se me olvidan ese tipo de cosas, entonces yo pago todas las cuentas y tú dame tu el dinero. Nosotros no peleamos por deporte, si peleamos es para solucionar y llegar a una conclusión, (...) así que como lo solucionamos, yo me hago cargo pásame tú el dinero, yo pago las cuentas y tú te haces cargo de otras cosas (...) Y lo hizo bien ya no hubo más conflictos.

Es posible apreciar acuerdos y negociaciones que pasan por la vigencia de un tipo de modelo en la pareja. En ese sentido, se observan distintos estilos: Es decir, a) tanto el hombre como la mujer administran los recursos, en familias mineras como no mineras; b) el pago de cuentas, simbolizado como carga o tramite, se delega a mujer; c) El hombre administra y se hace cargo del manejo de recursos. Finalmente, se puede observar que para el hombre no le es de gran importancia el hecho de quien gasta el dinero, sino más bien, le interesa mantener el lugar como proveedor y controlador de los recursos.

\subsection{Lugar del padre.}

Proveedor.

Hombre minero, 62 años, casado con 5 hijos, Calama.

Ella planificaba todo lo de la casa y yo así como cada tipo "estúpido" yo era como el proveedor, pero igual eso no quita de que salíamos a comer a fuera, o de vez en cuando a "valpo", pero las funciones de casa, yo no participaba mucho.

Mujer pareja de minero, 50 años, casada, dos hijos, Calama.

Es un pilar importante dentro de la familia tanto en la parte económica cómo en lo emocional. El mismo dice que su preocupación principal es que no nos haga falta nada, que a veces no puede pasar tanto tiempo como le gustaría en la casa o acompañándonos en lo que hacemos, pero que su preocupación por la familia se ve reflejada en que podemos vivir bien, quizás sin grandes lujos pero con todo lo necesario

Hombre no minero, 36 años, soltero, dos hijas. Antofagasta.

si...gasto harto en mis hijas, en ellas más que nada o sea tampoco son de andar pidiendo mucho pero lo que se gasta se trata de invertir bien, comprarle lo que ellas necesitan, de repente darle sus gustitos que no es malo, entonces si se ocupa bien la plata.

En cada uno de los relatos queda manifiesta la importancia del rol proveedor del hombre, que forma parte de una masculinidad socializada desde la familia de origen en el modelo de jerarquías androcentradas. El trabajador maneja y controla los recursos para cubrir las necesidades que aseguren el bienestar tanto familiar como propio y le posibilite mantenerse en la idea de jefatura. A su vez, esto puede ser apreciado como una presión de la masculinidad, dado que es un mandato implícito, que genera expectativas sobre el hombre y su posición de poder. Finalmente, rescatar la ironía del trabajador minero del relato, que alude al lugar del 'estúpido' proveedor, en donde deja en evidencia una valoración negativa de este mandato, sin embargo, no genera acciones en una dirección contraria a este lugar autoasignado.

\section{DISCUSIÓN}

A lo largo de esta investigación hemos buscado comprender la construcción sociocultural de masculinidades en la zona 
de Antofagasta, en ese sentido, destaca en primera instancia, el lugar en que se posicionan trabajadores mineros y no mineros como jefes de familia y proveedor del hogar. No obstante, hemos encontrado que la forma en que articulan su lugar como padres-trabajadores presenta algunas distinciones, de acuerdo con el sistema al que adscriben, el momento biográfico en que se encuentran, las oportunidades educativas a las que han accedido, si tienen hijos, entre otras (Lagarde, 2001).

El trabajador minero en la mayoría de los relatos, resalta su posición de autoridad como jefe de hogar y ser en la mayoría de los casos, el único proveedor económico en la familia. En este sentido, se hace de gran importancia el sistema de trabajo al que adscriben, ya que el trabajo en una empresa minera por turnos pasa a ser un eje a través del cual se desarrollan prácticas y dinámicas no solo del trabajador, sino que también de su familia. En el norte chileno, se encuentra instaurada la cultura minera que incita y fomenta la reproducción y mantenimiento de los discursos hegemónicos masculinos, vale decir, se insta a la construcción de masculinidades tradicionales, centradas en los tres pilares fundamentales descritos por Gilmore (2008), que son: Provisión, protección y potencia. Las mujeres e hijos también construyen subjetividad, intimidad y afectividad en torno a las disipaciones del tiempo libre que organizan las empresas con los trabajadores.

En las experiencias de este grupo de personas vinculadas a la minería, se concuerda con Lagarde (2001) dado que se logra apreciar la marcada distinción del sistema sexo/ género de jerarquías en las familias. En función de este sistema de turnos del trabajador minero, su presencia en la familia tiende a ser intermitente, con grandes periodos de ausencia, de manera tal que la mujer-madre, se sitúa como gestora del hogar, de la crianza y cuidado de los hijos y sus dinámicas integrales, quedando el padre, en una posición distante de estos procesos. De este modo, ella adquiere una carga importante de poder tanto con los hijos, como la administración de los recursos.

En el caso del trabajador no minero, se presenta mayor flexibilidad en sus prácticas; participando más activamente en la crianza y acompañamiento cotidiano de los hijos e hijas, y en la vida íntima afectiva con la pareja. Su presencia diaria en la dinámica familiar contribuye a una mayor capacidad de negociación de conflictos y participación tanto con la pareja como con los hijos e hijas. En este sistema de trabajo no minero, principalmente en parejas de adultos jóvenes (30-45 años) en que ambos aportan económicamente al hogar, se observa con mayor nitidez el cambio cultural hacia modelos de equidad y democracia de género, Aun así, se encontraron conflictos sujetos a otros elementos, tales como la diferencia en los niveles de ingreso, a partir de los cuales se da paso a otras alternativas de ingresos en la familia. En este sentido, los trabajadores no mineros se muestran dispuestos a ser el único sustento económico de la familia, en el caso de que se presentara la oportunidad, dando cuenta así de la vigencia de ambos modelos de género en este grupo, tanto el de énfasis en la jefatura masculina como en el de apertura hacia la equidad.

En términos afectivos y de intimidad con la pareja, tanto trabajadores mineros como no mineros asumen una emocionalidad no exteriorizada, bajo lo cual se aprecia un vínculo afectivo precarizado tanto con su pareja como con sus hijos. Lo anterior se comprende en base a la disposición del mandato androcentrado dominante, que señala que el hombre debe demostrar potencia, rudeza y agresividad. Al mismo tiempo, las características de la zona minera intensifican la construcción de una masculinidad hegemónica, basada en mandatos tradicionales e inflexibles. La precariedad de la expresión de la 
afectividad, se amalgama con la cultura de consumo privilegiada en la sociedad chilena. Esta combinación enlaza afectividad con la satisfacción de las necesidades afectivas propias y de la pareja y los hijos, mediante regalos y compra de objetos materiales.

En este contexto, el posicionamiento de los trabajadores como padre y su lugar en la familia, se encuentra permeado por la cultura minera, sean éstos empleados o no de las empresas mineras. Es decir, una cultura que otorga alto valor a los recursos económicos que van aparejados de la representación de sacrificio y riesgo.

Así también se distinguen los niveles de conflictividad, sin que los estilos de paternidad y de ser pareja sean muy diferentes. Se observa vigencia de androcentrismo en ambos grupos de hombres y también en los testimonios de mujeres. Es decir, la conflictividad entre los trabajadores por turnos es mayor por la presencia y ausencia del grupo familiar.

Así, adquiere gran relevancia el sistema laboral minero, el cual en diversas ocasiones, no compatibiliza el bienestar de los sujetos con los ideales de producción en la explotación cuprífera, bajo lo cual los trabajadores tienden a ser objetivizados. De esta manera, la construcción de la masculinidad y la precariedad del sujeto como padre y pareja, no puede ser abarcado únicamente como una carencia en los sujetos propiamente tales, sino que también es importante comprender cómo las instituciones en las que se encuentra inmerso el sujeto son parte de la forma en que este es construido.

Ahora bien, se aprecia en generaciones más jóvenes algunas modificaciones en las prácticas más tradicionales, que denota una tendencia hacia el cambio y la vivencia hacia nuevos estilos de masculinidad; con mayor participación y compromiso en la crianza, las actividades del hogar y la pareja. Lo anterior se ve opacado por la existencia de michomachismos, que mantienen practicas sutiles y ocultas de relación de poder hombre-mujer en situaciones cotidianas, bajo lo cual se concuerda con el Instituto Vasco de la Mujer (2008), que si bien existe un avance con respecto a nuevas masculinidades, se evidencian ciertos obstáculos para ello.

Consideramos que para futuras investigaciones, han quedado nudos por desarrollar: Por ejemplo, aquellos tópicos que consideren aspectos generacionales; el trabajador adulto mayor y los modelos de construcción de su masculinidad, articulados al nivel socioeconómico y educativo. Asimismo, la comparación entre hombres y mujeres trabajadores en sector minería. 
REFERENCIAS

Badinter, E. (1993). XY La identidad masculina. Madrid, España: Alianza.

Carabí, A. \& Armengol (EDS) (2008). La masculinidad a debate. Barcelona, España: Icaria editorial S.A.

Careaga, G. Cruz, S. (2006).Debates sobre Masculinidades, Poder, desarrollo, políticas públicas y ciudadanía, Programa Universitario de Estudios de Género. Distrito federal, México: UNAM.

Carrasco, C. Vega, P. (2011).Una aproximación a las condiciones de trabajo en la gran minería de altura. Santiago de Chile: Dirección del trabajo, gobierno de Chile

Connell, R. (1995). La organización social de la masculinidad. En: Valdés, T. y Olavarría, J.(Eds.). (1997). Masculinidad/es: poder y crisis. Santiago, Chile: FLACSO: ediciones de las mujeres

Connell, R. (1998). El imperialismo y el cuerpo de los hombres. Santiago: FLACSO.

Cruz, S. (2011). Sentido y práctica de la intimidad masculina: Una mirada desde los hombres. Sociológica. México.

De Barbieri, T. (1996). Los ámbitos de acción de las mujeres. En Henríquez, N. (ed.) (1996). Encrucijadas del saber: los estudios de género en las ciencias sociales. Lima: Pontificia universidad católica del Perú.

Donoso, C. (2002) ¿Eros sentimental? Explorando los desafíos de la sexualidad masculina, en Olavarría, J. Moletto, E. Hombres: identidad/es y sexualidad/es $3^{\circ}$ Encuentro de Estudio de Masculinidades. Santiago, Chile: FLACSO.

Figueroa, J. (2001). La soledad en la paternidad. Fem, 218(25). 15-19.

Fuller, N. (1997).Identidades masculinas, varones de clase media en el Perú. Lima: Fondo Editorial de la Pontificia Universidad Católica del Perú
Fuller, N. (2001).Masculinidades. Cambios y permanencias. Lima, Perú: Pontificia Universidad Católica del Perú.

García, M. (2004). Dominación de Género y actores políticos. En Olavarría, J. Márquez, A. (Eds.) (2004) Varones: entre lo público y la intimidad. $37-42$. Santiago, Chile: FLACSO.

Giddens, A. (1998). Sociedad de riesgo: el contexto de la política británica. Estudios Demográficos y Urbanos, $13,3,517-528$.

Gilmore, D. (2008). Culturas de la masculinidad. En Carabí, A., Armengol, J. (Eds.) (2008). La masculinidad a debate. 33 - 46. Barcelona: Icaria.

Guzmán, M., Contreras P. (2012). Estilos de apego y su Asociación con la satisfacción marital. Psykhe, 21(1). 69 $-82$.

Instituto Vasco de la Mujer (2008). Los hombres, la igualdad y las nuevas masculinidades Vitoria-Gasteiz, España. Editoral Emakunde-Instituto Vasco de la Mujer Manuel Iradier. http://www.mercurioantofagasta.cl/pront us4_noticias/site/artic/20100126/pags/2 0100126000515.html

Kaufman, J, C (1999). La ropa sucia. En Ulrich Beck, Hijos de la Libertad. Buenos Aires, Argentina: Fondo de Cultura Económica.

Klubock, T. (1992). Sexualidad y proletarización en la mina El Teniente. Preposiciones, 21. $45-54$.

Lamas, M. (2003). El género: La construcción cultural de la diferencia sexual. México: Miguel Angel Porrua, libro- editor.

Lagarde, M. (2001). Los cautiverios de las mujeres: Madresposas, monjas, putas, presas y locas. Distrito Federal, México: UNAM

Meller, P. (2013) La viga maestra y el sueldo de Chile, Mirando el futuro con los ojos del cobre. Santiago, Chile. Uqbar ediciones.

Muñiz, E. (2002) Cuerpo, representación y poder. México en los albores de la reconstrucción nacional, Porrúa- 
Universidad Autónoma Metropolitana, unidad Azcapot-zalco, México D. F.

Olavarría, J.; Benavente, C. y Mellado, P. (1998). Masculinidades populares. Varones adultos jóvenes de Santiago. Santiago, Chile: FLACSO.

Olavarría, J. (2001) ¿Hombres a la deriva? Poder, trabajo y sexo. Santiago, Chile: FLACSO.

Olavarría, J. (2000). Ser padre en Santiago de Chile. En Fuller, N. (Ed.) (2000). Paternidades en América Latina. 129173. Lima, Perú: Pontificia Universidad Católica del Perú, Fondo Editorial.

Olavarría, J. (2004). Modelos de masculinidad y desigualdades de género. En Lomas, C. (Coord.) (2004) Los chicos también Iloran: identidades masculinas, igualdad entre los sexos y coeducación. 45 - 65.

Palacios, M; Valencia, A. (2001) La identidad masculina: un mundo delnclusiones y exclusiones. Manizales, Colombia: Editorial Universidad de Caldas.

Parrini, R (2000) Apuntes acerca de los estudios de la masculinidad, de la hegemonía a la pluralidad. Santiago, Chile. FLACSO-Chile, 2000.

Rivas, A. Rodríguez, M. (2008) Mujeres y Hombres en conflicto. Trabajo, familia y desigualdad de género, en Caamaño, E. (2010). Mujeres y trabajo: Origen y Ocaso del modelo del padre proveedor y la madre cuidadora. Universidad Católica de Valparaíso, Chile.

Salguero, A. (2008). Identidad masculina. Elementos de análisis en el proceso de construcción. México: UNAM.

Salinas, P., Reyes, C., Romaní, G., Ziede, M. (2010). Mercado laboral femenino. Un estudio empírico, desde la perspectiva de la demanda, en la región minera de Antofagasta, Chile. INNOVAR, Revista de Ciencias Administrativas y Sociales, 20(38), 125 $-139$.

Scott, J. (1999). Gender and the Politics of History. EE.UU.:Columbia University Press
Silva, J. (2013). Grafías del cuerpo, discursos y sujeciones corporales. En Silva, J. \& Méndez, L. (eds.) (2013). Cuerpos y metáforas. Estudio de los significados culturales del cuerpo y las sexualidades juveniles. AntofagastaChile: EMELNOR/CONICYT.

Valdés, T. y Olavarría, J. (1998) "Ser hombre en Santiago de Chile: a pesar de todo, un mismo modelo", en Valdés, T. y J. Olavarría (eds). (1998). Masculinidades y equidad de género en América Latina. Santiago, Chile: FLACSO

Weeks, J. (1998). Sexualidad. Mexico: Edit.Paidos. 